\title{
Fabrication of Nano-Sized ITO Powder from Waste ITO Target by Spray Pyrolysis Process
}

\author{
Jae-Keun $\mathrm{Yu}^{1}$, Seong-Gu Kang ${ }^{2}$, Ki-Chang Jung ${ }^{3}$, Joung-Su Han ${ }^{4}$ and Dong-Hee Kim ${ }^{5}$ \\ ${ }^{1}$ Department of Advanced Materials Engineering, Hoseo University, Asan 336-795, Korea \\ ${ }^{2}$ Department of Chemical Engineering, Hoseo University, Asan 336-795, Korea \\ ${ }^{3}$ Department of Safety System Engineering, Hoseo University, Asan 336-795, Korea \\ ${ }^{4}$ Technology Innovation Center, Hoseo University, Asan 336-795, Korea \\ ${ }^{5}$ Department of Anesthesiology, Dankook University, Cheonan 330-714, Korea
}

In this study, a nano-sized ITO powder with the average particle size below $50 \mathrm{~nm}$ by using waste ITO target is generated by spray pyrolysis proces. This study also examines the influences of reaction parameters such as reaction temperature, concentration and inflow speed of raw material solution on the properties of the generated ITO powder.

As the reaction temperature increases from $800^{\circ} \mathrm{C}$ to $1100^{\circ} \mathrm{C}$, the average particle size of the generated ITO powder increases from $40 \mathrm{~nm}$ to $100 \mathrm{~nm}$, the microstructure gradually becomes compact, the particle size distribution becomes increasingly irregular, the XRD peak intensity gradually increases, and the specific surface area decreases.

When the concentration of the solution is at $50 \mathrm{~g} / \mathrm{L}$, the average particle size of the ITO powder is below $30 \mathrm{~nm}$, and the particle size distribution appears comparatively uniform. As the concentration reaches $400 \mathrm{~g} / \mathrm{L}$, which is close to the saturated concentration, the particle size distribution appears extremely irregular, and the particles with the size ranging from $20 \mathrm{~nm}$ to $100 \mathrm{~nm}$ coexist. Along with the rise of concentration, the XRD peak intensity gradually increases, yet the specific surface area decreases.

As the inflow speed of the raw material solution increases from $2 \mathrm{~mL} / \mathrm{min}$ to $100 \mathrm{~mL} / \mathrm{min}$, the average particle size of the ITO powder increases from $30 \mathrm{~nm}$ to $90 \mathrm{~nm}$, yet the particle size distribution becomes irregular, and individual particles appear in the distinct shape of polygon. Along with the rise of inflow speed, the XRD peak intensity gradually increases, and the specific surface area decreases. [doi: $10.2320 /$ matertrans.48.249]

(Received September 21, 2006; Accepted December 4, 2006; Published January 25, 2007)

Keywords: waste indium-tin oxide target, spray pyrolysis, nano-sized indium-tin oxide powder, reaction factors, average particle size

\section{Introduction}

Along with the rapid development of information and telecommunication industry, several types of flat panel display have been developed and put into practical use in many industrial fields, e.g. the manufactures of television set, mobile phone, office equipments, etc. For the manufacture of these flat panel displays, a transparent electrode must be utilized, and this electrode is required to have high electrical transmissivity within the visible spectrum, and excellent electrical conductivity and electromagnetic wave shielding ability. ITO (Indium Tin Oxide) film made from ITO target by sputtering method can satisfactorily serve this purpose. Consequently, research activities related to the manufacture of ITO film and its property enhancement are being conducted actively. ${ }^{1-5)}$ However, there hasn't been too much research effort regarding the effective recycling of waste ITO target generated from the manufacturing process of ITO film. Ideally, ITO target is required to have excellent sinterability, but practically ITO target is an unsinterable material. Because of the intense dissociation and volatilization of $\mathrm{In}_{2} \mathrm{O}_{3}$ and $\mathrm{SnO}_{2}$ at very high temperature, it's difficult to sinter ITO target to above $70 \%$ of its theoretical density under normal pressure. Currently, together with the manufacture of nano-sized ITO powder, ${ }^{6,7)}$ there are many ongoing research activities related to the manufacture of high density sinter by enhanced densification and driving force. ${ }^{8,9)}$

The purpose of this study is to develop an effective recycling technology for waste ITO target by spray pyrolysis process. ${ }^{10-14)}$ In this study, waste ITO target is dissolved into hydrochloric acid to generate a complex solution. By using this solution as the raw material, a nano-sized ITO powder with uniform particle size and average particle size below $50 \mathrm{~nm}$ is generated by spray pyrolysis process. This study also examines the influences of various reaction parameters on the properties of the generated ITO powder. These parameters include the reaction temperature, the concentration and inflow speed of the raw material solution.

\section{Experimental}

In this study, by using spray pyrolysis process, waste ITO target is utilized as the raw material to manufacture the ITO powder with average particle size below $50 \mathrm{~nm}$. The purity of the waste ITO target is above $99.9 \%$, and the contents of $\mathrm{SiO}_{2}, \mathrm{P}, \mathrm{Ca}, \mathrm{Cr}$ and $\mathrm{Cu}$ are below $100 \mathrm{ppm}$. Waste ITO target is firstly dissolved into an $\mathrm{HCl}$ solution with the concentration of $25 \%$ till the indium concentration of the solution is adjusted to $400 \mathrm{~g} / \mathrm{L}$. Then, the solution was filtered triply through filter paper, and the purified solution is utilized as the raw material of the spray pyrolysis process. This almost saturated solution is diluted by distilled water so that the indium concentration of the solution is adjusted to 320, 160 and $50 \mathrm{~g} / \mathrm{L}$. The content of tin is added into the solution so that the ratio between $\mathrm{In}_{2} \mathrm{O}_{3}$ and $\mathrm{SnO}_{2}$ in the ITO powder is 9:1 in mass ratio.

In order to generate an ultra fine solid powder with uniform particle size and shape, an efficient spray pyrolysis system is specially designed and built for this study. This system enables the following features: the raw material solution can be sprayed into the reaction furnace after being efficiently micronized, the pyrolysis reaction can be completed perfectly 
inside the reaction furnace, the generated powder can be collected effectively by a powder collection device named bag filter, and the toxic gases generated in the process can also be cleansed by a scrubber. The schematic diagram of this system is shown in Fig. 1.

In this study, the raw material solution is fed into an inlet of the nozzle by a micro quantifying pump with the inflow speed ranging from $2 \mathrm{~mL} / \mathrm{min}$ to $100 \mathrm{~mL} / \mathrm{min}$, while the pressurized air is fed into the other inlet of the nozzle so that the solution can be micronized into fine droplets. Solution is in turn sprayed into the 4 zone reaction furnace with the inside temperature adjustable from $800^{\circ} \mathrm{C}$ to $1100^{\circ} \mathrm{C}$. Subsequently, nano-sized ITO powders are collected by the collection device. Given the various reaction temperature, concentration and inflow speed of the raw material solution, the properties of the correspondingly generated powder are examined according to TEM, SEM, XRD analysis and the measurement of specific surface area.

\section{Results and Discussion}

\subsection{Powder properties influenced by reaction temper- ature}

Figure 2 is the result of SEM analysis, which shows the

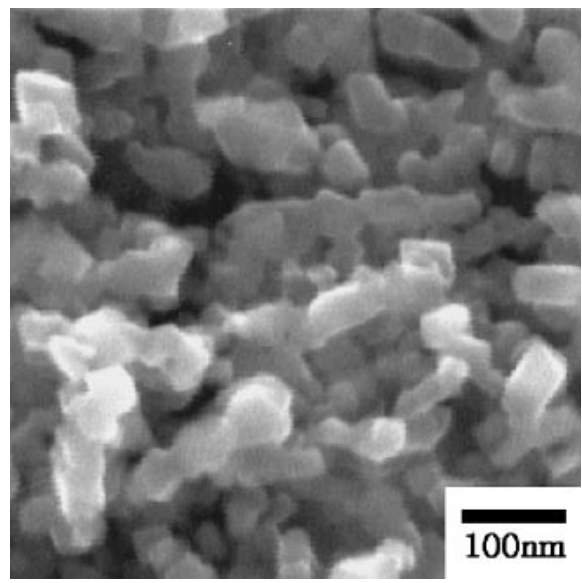

(a)

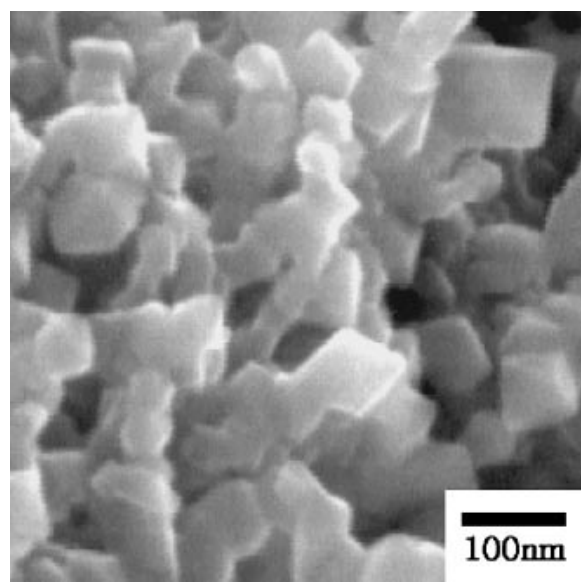

(c)

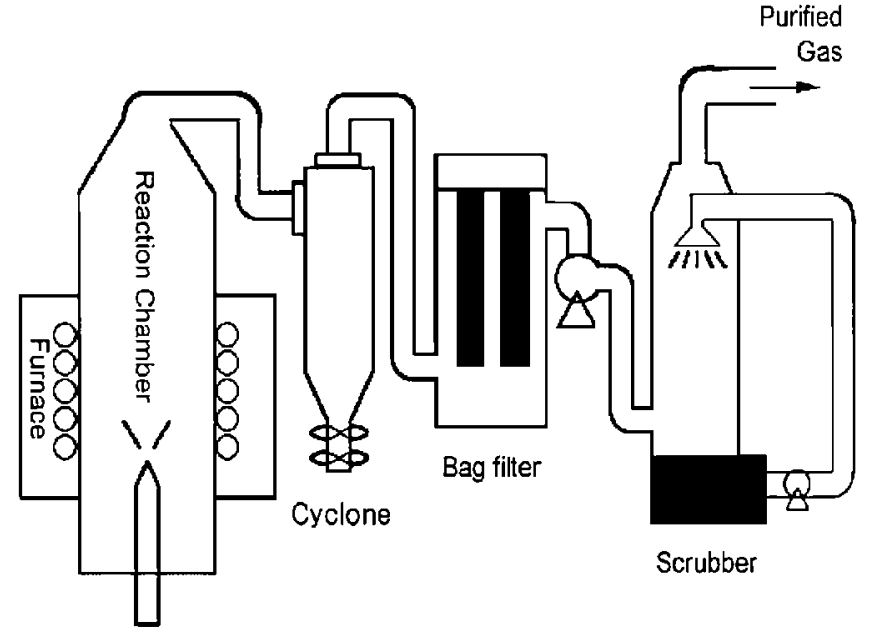

Titanium Nozzle

Fig. 1 Schematic diagram of spray pyrolysis system.

property change of the generated powder relative to the rise of reaction temperature from $800^{\circ} \mathrm{C}$ to $1100^{\circ} \mathrm{C}$, given that the indium concentration of the raw material solution is kept at $320 \mathrm{~g} / \mathrm{L}$, the tin concentration in the raw material solution at

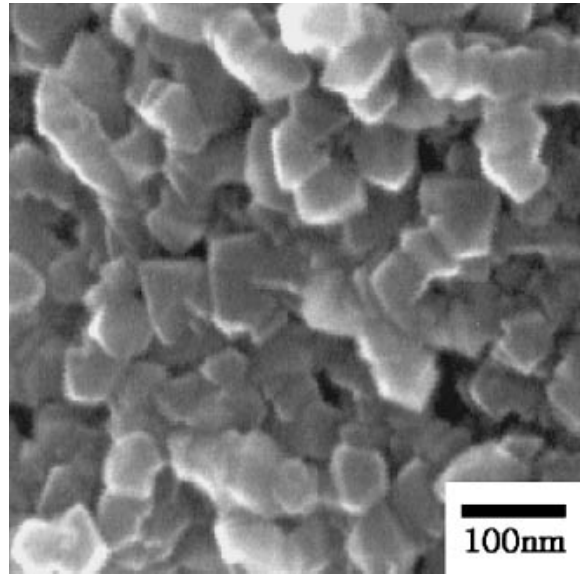

(b)

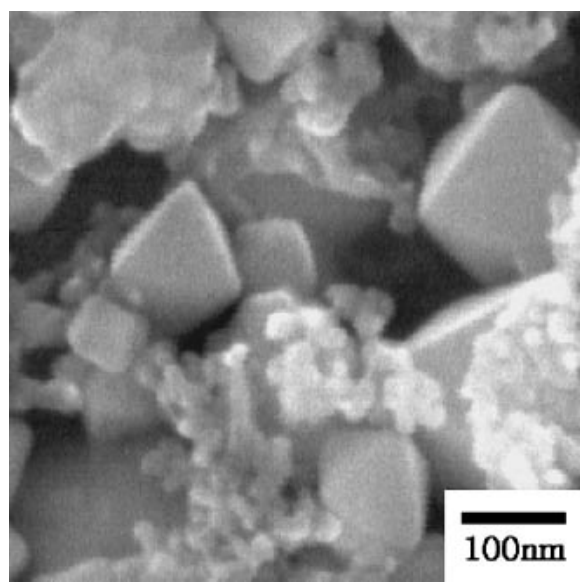

(d)

Fig. 2 SEM photographs of produced powder according to reaction temperature at raw material solution of $320 \mathrm{~g} / \mathrm{L} \mathrm{indium,} 10 \mathrm{~mL} / \mathrm{min}$. inlet speed of solution, $2 \mathrm{~mm}$ nozzle tip size and $1 \mathrm{~kg} / \mathrm{cm}^{2}$ air pressure. (a) $800^{\circ} \mathrm{C}$, (b) $900^{\circ} \mathrm{C}$, (c) $1000^{\circ} \mathrm{C},(\mathrm{d}) 1100^{\circ} \mathrm{C}$. 
$34 \mathrm{~g} / \mathrm{L}$ (in order that the ratio between $\mathrm{In}_{2} \mathrm{O}_{3}$ and $\mathrm{SnO}_{2}$ in the generated ITO powder is 9:1), the inflow speed of the raw material solution at $10 \mathrm{~mL} / \mathrm{min}$, the nozzle tip size at $2 \mathrm{~mm}$, and the air pressure at $1 \mathrm{~kg} / \mathrm{cm}^{2}$. It can be seen from Fig. 2 that, along with the rise of reaction temperature, the particle size increases accordingly, and the powder structure becomes much more compact. The raw material solution becomes micronized droplets after passing through the nozzle. The micronized droplets flow into the reaction furnace, and then are subject to the pyrolysis reaction. In turn, the solute is solidified and extracted on the surface of the droplets. Thus, the solvent inside the droplets cannot get through the solidified surface layer easily. As a result, caused by the continuously elevated interior pressure, the droplets would eventually burst. The higher the concentration of the raw material solution and the surrounding temperature, the severer the droplet burst. When the reaction temperature is at $800^{\circ} \mathrm{C}$, as soon as the micronized droplets flow into the reaction zone, the surface solvent is rapidly vaporized, which causes the droplets to burst severely. Because of the extremely narrow reaction zone, and because the reaction temperature of $800^{\circ} \mathrm{C}$ cannot ensure the sufficient sintering of the fine solid powder, the generated powder appears with an average particle size of $40 \mathrm{~nm}$, and the ultra fine particles shows a strong tendency of mutual cohesion. Since there is no significant droplet burst at the comparatively low reaction temperature, the particle size distribution of the generated powder appears more uniform in contrast to the situations at other reaction temperatures. When the reaction temperature increases up to $900^{\circ} \mathrm{C}$, because of the more rapid evaporation of the solvent along with the temperature rise, the solute at droplet surface rapidly becomes over-saturated, and the droplet burst at the initial stage of the spray pyrolysis process appears much severer. On the other hand, because of the temperature rise, the sintering of the initially generated ultrafine particles proceeds further, the average particle size reaches $50 \mathrm{~nm}$, many particles grow in the shape of polygon, and the particle structure appears more compact in contrast to the situation at $800^{\circ} \mathrm{C}$. When the reaction temperature increases up to $1000^{\circ} \mathrm{C}$, as the result of high temperature, the solidification reaction proceeds instantly at droplet surface, the pressure inside droplets increases significantly, and the droplet burst at the initial stage of spray pyrolysis reaction appears much severer. Although the particle size at the initial stage appears extremely small, because the sintering of particles proceeds extremely fast due to the high reaction temperature, the particle size distribution appears so irregular that particles with the size ranging from $30 \mathrm{~nm}$ to $80 \mathrm{~nm}$ coexist. On the other hand, there is collectively a slight rise of average particle size in contrast to the situation at $900^{\circ} \mathrm{C}$, the particle surface become more compact, and most of the particles appear in the shape of mutually independent polygon. When the reaction temperature increases up to $1100^{\circ} \mathrm{C}$, because of the instant over-saturation on the droplet surface and the pressure rise inside the droplets, the severe droplet burst occurs. Although the particle size at the initial stage appears extremely small, because the sintering of particles proceeds extremely fast due to the high reaction temperature, the particle size distribution appears so irregular that powders with the particle size ranging from $20 \mathrm{~nm}$ to

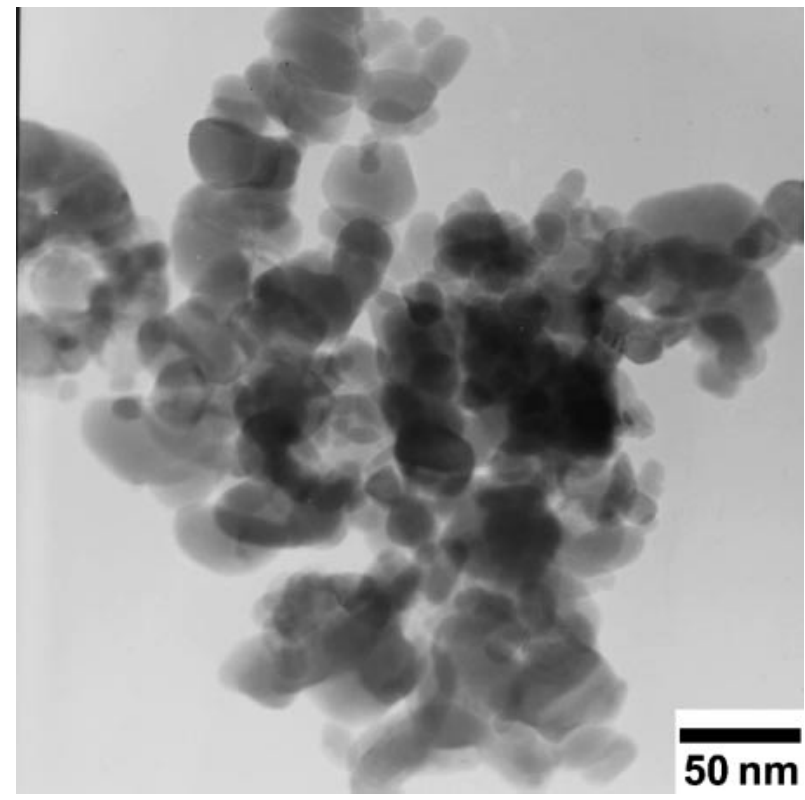

(a)

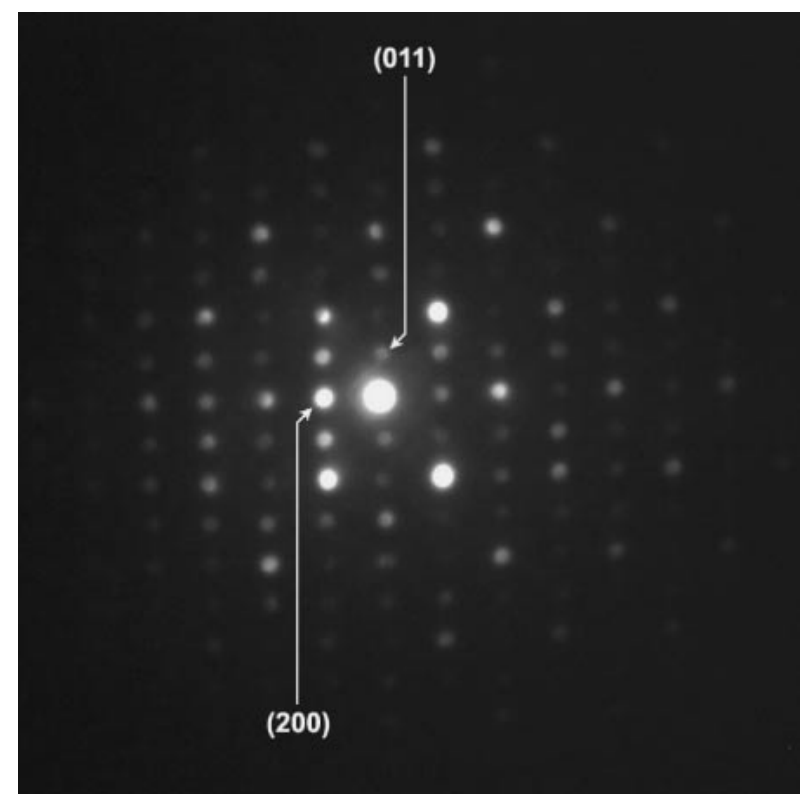

(b)

Fig. 3 TEM photographs of produced powder and selective diffraction pattern of single particle at reaction temperature of $900^{\circ} \mathrm{C}$, raw material solution of $320 \mathrm{~g} / \mathrm{L}$ indium, $10 \mathrm{~mL} / \mathrm{min}$. inlet speed of solution, $2 \mathrm{~mm}$ nozzle tip size and $1 \mathrm{~kg} / \mathrm{cm}^{2}$ air pressure. (a) TEM photographs of produced powder. (b) Selective diffraction pattern of single particle.

$100 \mathrm{~nm}$ coexist. On the other hand, the average particle size is collectively around $80 \sim 90 \mathrm{~nm}$, which increases significantly in contrast to the situation at $1000^{\circ} \mathrm{C}$, the particle surface becomes more compact, and most of the particles appear in the shape of mutually independent polygon.

Figure 3 is the result of TEM analysis, which shows the structural property of the generated powder and the selective diffraction pattern of single particle. And selective diffraction patterns of other particles were same with Fig 3. With these results, we concluded that generated particles were composed of solid single crystal. 


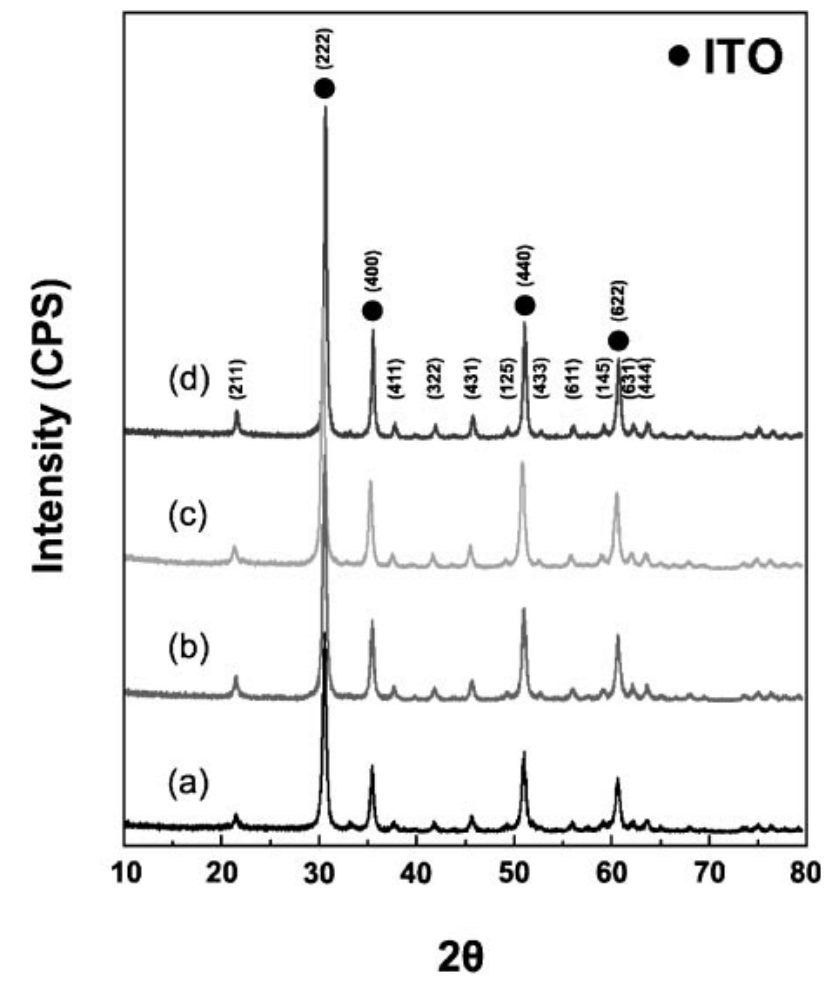

Fig. 4 XRD patterns of powder according to reaction temperature at raw material solution of $320 \mathrm{~g} / \mathrm{L}$ indium, $10 \mathrm{~mL} / \mathrm{min}$. inlet speed of solution, $2 \mathrm{~mm}$ nozzle tip size and $1 \mathrm{~kg} / \mathrm{cm}^{2}$ air pressure. (a) $800^{\circ} \mathrm{C}$, (b) $900^{\circ} \mathrm{C}$, (c) $1000^{\circ} \mathrm{C}$, (d) $1100^{\circ} \mathrm{C}$.

Figure 4, the results of XRD analysis under the same reaction conditions as in Fig. 2, shows the phases of the generated powder and the corresponding Miller index of each peak relative to the change of reaction temperature. It can be seen from Fig. 4 that only ITO phase is exist, and the corresponding Miller indexes of individual peaks maintain at a fixed level regardless of the reaction temperature. When the reaction temperature is at the lowest $850^{\circ} \mathrm{C}$, there is no unreacted products of indium chloride and tin chloride. Hence, it can be concluded that, within the temperature range of the reaction furnace, the pyrolysis reaction proceeds completely despite the short reaction time. As the reaction temperature increases from $800^{\circ} \mathrm{C}$ to $1100^{\circ} \mathrm{C}$, the XRD peak intensity gradually increases, and there is a significant rise of $\mathrm{XRD}$ peak intensity especially at $1100^{\circ} \mathrm{C}$. This result, consistent with what is shown in Fig. 2, is owing to the facts that the average particle size of the generated ITO powder increases along with the rise of reaction temperature, and that the average particle size increases significantly at $1100^{\circ} \mathrm{C}$. On the other hand, when the reaction temperature is at $1000^{\circ} \mathrm{C}$, the size of large particles increases significantly in contrast to the situation at $900^{\circ} \mathrm{C}$, though the particle size distribution appears irregular, and a significant amount of small particles exist. As a result, there is no significant rise of $\mathrm{XRD}$ peak intensity as the reaction temperature increases from $900^{\circ} \mathrm{C}$ to $1000^{\circ} \mathrm{C}$.

Figure 5 shows the specific surface area of the generated powder relative to the reaction temperature under the same reaction conditions as in Fig. 2. It can be seen from Fig. 5 that, the specific surface area of the generated powder

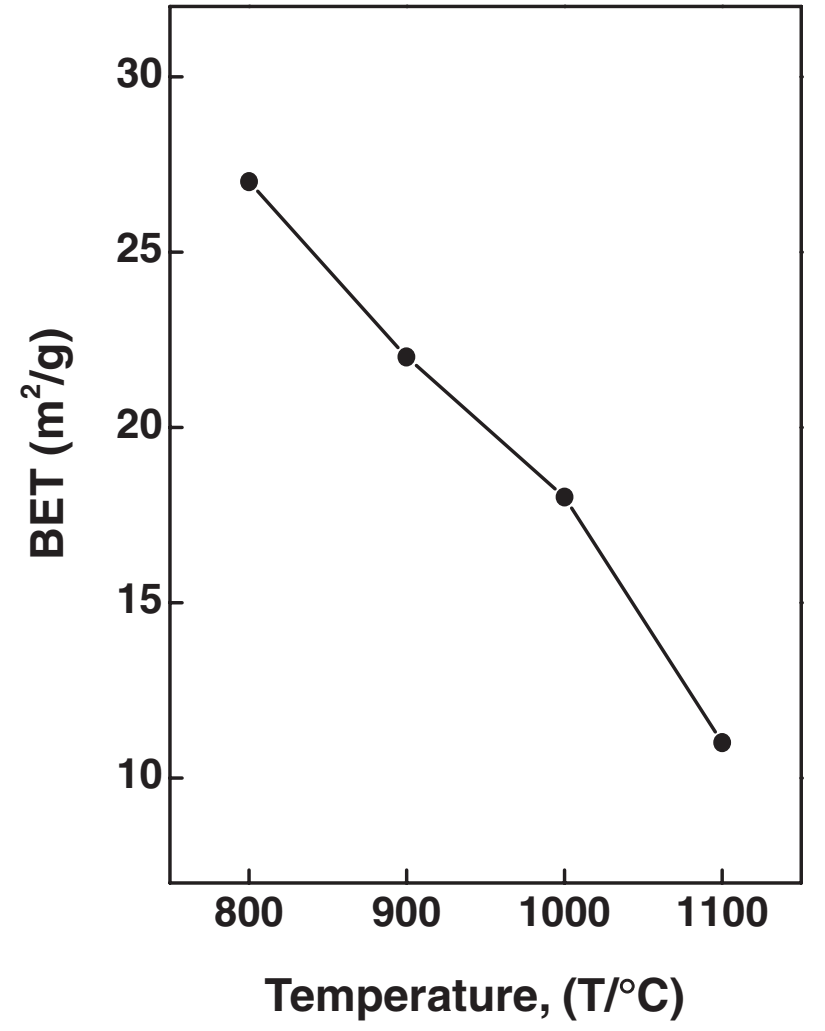

Fig. 5 Specific surface areas of powder according to reaction temperature at raw material solution of $320 \mathrm{~g} / \mathrm{L}$ indium, $10 \mathrm{~mL} / \mathrm{min}$. inlet speed of solution, $2 \mathrm{~mm}$ nozzle tip size and $1 \mathrm{~kg} / \mathrm{cm}^{2}$ air pressure.

decreases along with the rise of reaction temperature, and that there is significant drop at $1100^{\circ} \mathrm{C}$. This result, consistent with what is shown in Fig. 2, is owing to the facts that the average particle size of the generated ITO powder increases along with the rise of reaction temperature, and that the particle structure becomes more compact.

\subsection{Powder properties influenced by the concentration of raw material solution}

Figure 6 is the result of SEM analysis, which shows the property change of the generated powder relative to the indium concentration of the raw material solution, given the reaction temperature is kept at $900^{\circ} \mathrm{C}$, the inflow speed of the raw material solution at $10 \mathrm{~mL} / \mathrm{min}$, the nozzle tip size at $2 \mathrm{~mm}$, and the air pressure at $1 \mathrm{~kg} / \mathrm{cm}^{2}$. It can be seen from Fig. 6 that, as the indium concentration increases from 50 $\mathrm{g} / \mathrm{L}$ to $400 \mathrm{~g} / \mathrm{L}$, the average particle size of the generated powder increases gradually, yet the particle size distribution becomes increasingly irregular. When the indium concentration is at the lowest $50 \mathrm{~g} / \mathrm{L}$, the droplet size appears extremely small after the evaporation of solvent. Due to the large amount of heat of evaporation, the magnitude of droplet burst is lessened during the process of evaporation. Also, since the over-saturation at the droplet surface and the pressure rise inside droplets diminishes greatly, the magnitude of droplet burst is lessened during the process of spray pyrolysis reaction. As a result, the eventually generated powder appears with an extremely small average particle size of below $30 \mathrm{~nm}$, yet the distribution of the particle size appears considerably uniform. When the concentration 


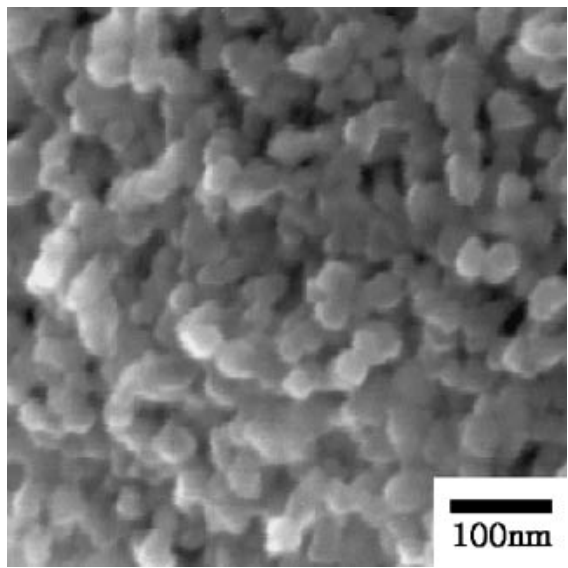

(a)

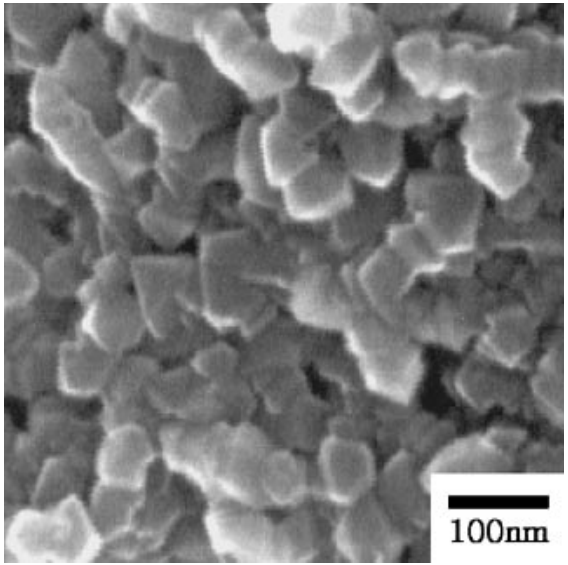

(c)

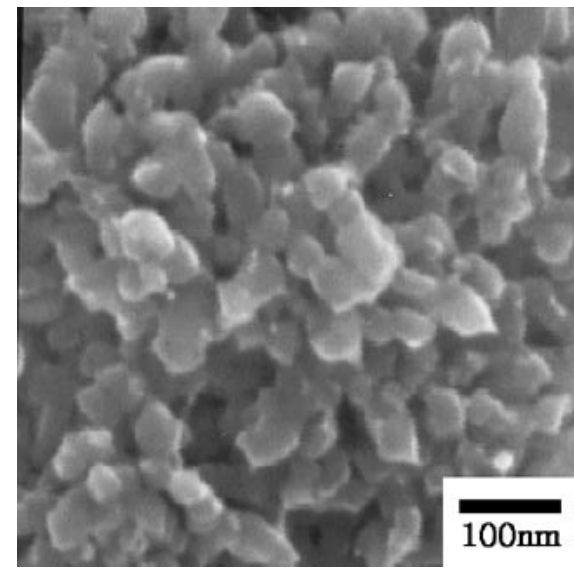

(b)

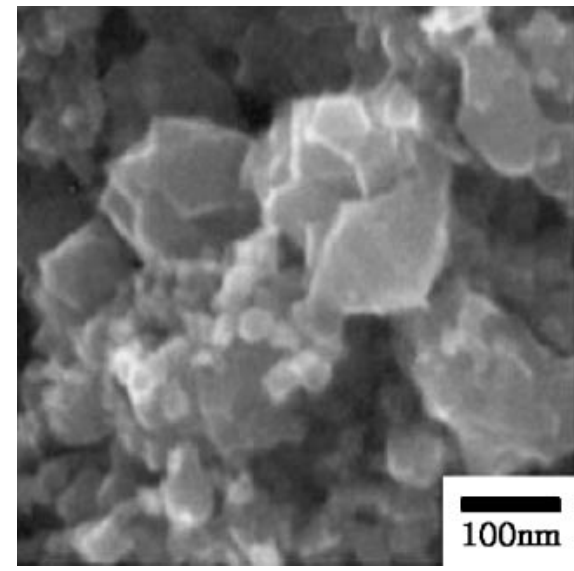

(d)

Fig. 6 SEM photographs of produced powder according to indium concentration of raw material solution at $900^{\circ} \mathrm{C}, 10 \mathrm{~mL} / \mathrm{min}$. inlet speed of solution, $2 \mathrm{~mm}$ nozzle tip size and $1 \mathrm{~kg} / \mathrm{cm}^{2}$ air pressure. (a) $50 \mathrm{~g} / \mathrm{L}$, (b) $160 \mathrm{~g} / \mathrm{L}$, (c) $320 \mathrm{~g} / \mathrm{L}$, (d) $400 \mathrm{~g} / \mathrm{L}$.

increases up to $160 \mathrm{~g} / \mathrm{L}$, there is no significant drop of the droplet size after the evaporation of solvent in contrast to the situation at $50 \mathrm{~g} / \mathrm{L}$, the droplet burst becomes severer during the pyrolysis reaction, and the particle size distribution becomes more irregular. After the evaporation of solvent, due to the rise of droplet size, the average particle size of the generated powder increases up to $40 \mathrm{~nm}$, and the particles collectively appear in the shape of sphere. When the concentration increases up to $320 \mathrm{~g} / \mathrm{L}$, the average particle size of the generated powder increases up to $50 \mathrm{~nm}$, yet the particle size distribution becomes more irregular, and most of the generated particles appear in the shape of polygon. This result is believed to be the combined effect of the following two mechanisms: 1) the droplet size increases along with the concentration rise after the evaporation of solvent; and 2) the droplet burst becomes severer during the pyrolysis reaction along with the rise of concentration. When the concentration increases up to $400 \mathrm{~g} / \mathrm{L}$, which is close to the saturated concentration, because the solute is excessively saturated on the droplet surface at the initial stage of pyrolysis reaction, the decrease of droplet size caused by the evaporation of solvent is almost undetectable, and the droplet size increases greatly in contrast to the situations at low concentrations. However, because of the severe droplet burst during the pyrolysis process, the particle size distribution appears so irregular that particles with the size ranging from $20 \mathrm{~nm}$ to $100 \mathrm{~nm}$ coexist.

Figure 7, the results of XRD analysis under the same reaction conditions as in Fig. 6, shows the phases of the generated powder and the corresponding Miller index of each peak relative to the change of concentration. It can be seen from Fig. 7 that, no matter what concentration the solution is at, there is only the form of ITO existing, no independent form of $\mathrm{SnO}_{2}$ exists. Also, no matter what concentration the solution is at, the corresponding Miller indexes of individual peaks maintain at a fixed level. When the concentration is at the lowest $50 \mathrm{~g} / \mathrm{L}$, there is no unreacted products of indium chloride, tin chloride and tin oxide. Hence, it can be concluded that the pyrolysis reaction proceeds completely. As the concentration increases from $50 \mathrm{~g} / \mathrm{L}$ to $400 \mathrm{~g} / \mathrm{L}$, the XRD peak intensity gradually increases. This result, consistent with what is shown in Fig. 6, is owing to the fact that the average particle size of the generated ITO powder is proportional to the concentration of raw material solution. For a low concentration, because the evaporation of solvent inside droplets takes a considerably long time in the reaction furnace, and because the heat of evaporation increases, the generating and growing speed of ITO powder in the pyrolysis 


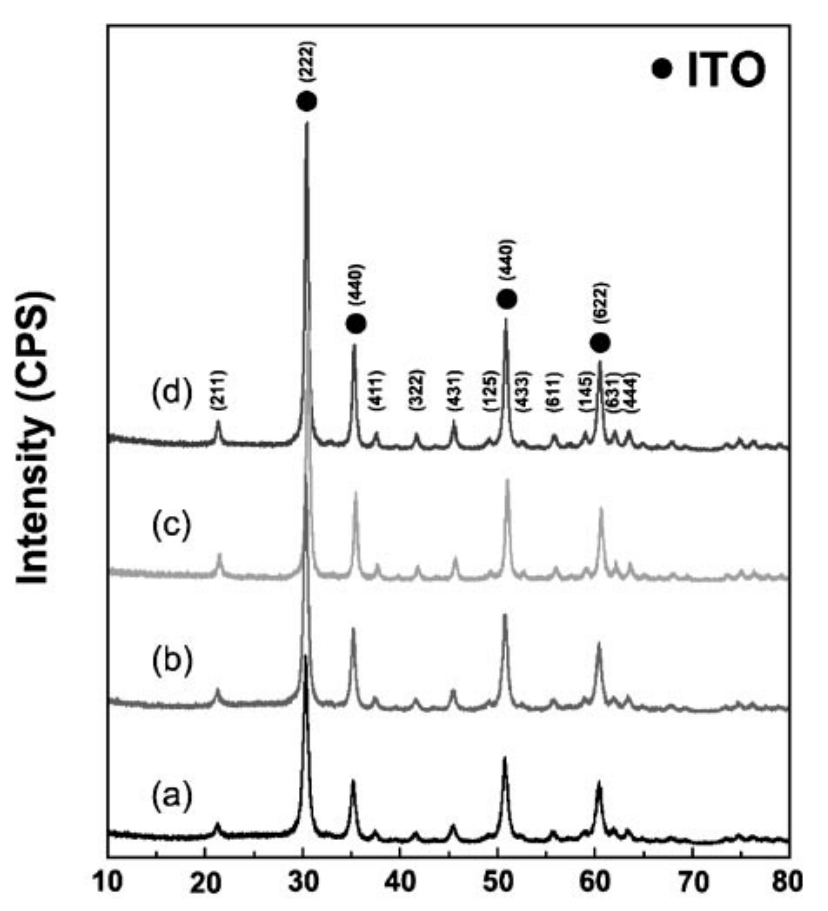

$2 \theta$

Fig. 7 XRD patterns of powder according to indium concentration of raw material solution at $900^{\circ} \mathrm{C}, 10 \mathrm{~mL} / \mathrm{min}$. inlet speed of solution, $2 \mathrm{~mm}$ nozzle tip size and $1 \mathrm{~kg} / \mathrm{cm}^{2}$ air pressure. (a) $50 \mathrm{~g} / \mathrm{L}$, (b) $160 \mathrm{~g} / \mathrm{L}$, (c) $320 \mathrm{~g} / \mathrm{L}$, (d) $400 \mathrm{~g} / \mathrm{L}$.

process decrease significantly. While for a high concentration, because of the rapid evaporation of solvent inside droplets, the generating and growing speed of ITO powder greatly increase.

Figure 8 shows the specific surface area of the generated powder relative to the concentration under the same reaction conditions as in Fig. 6. It can be seen from Fig. 8 that, the specific surface area of the generated powder gradually decreases along with the concentration rise. This result, consistent with what is shown in Fig. 6, is owing to the fact that the average particle size of the generated ITO powder is proportional to the concentration of raw material solution.

\subsection{Powder properties influenced by the inflow speed of raw material solution}

Figure 9 is the result of SEM analysis, which shows the property change of the generated powder relative to the inflow speed of the raw material solution, given that the reaction temperature is kept at $900^{\circ} \mathrm{C}$, the indium concentration of the raw material solution at $320 \mathrm{~g} / \mathrm{L}$, the nozzle tip size at $2 \mathrm{~mm}$, and the air pressure at $1 \mathrm{~kg} / \mathrm{cm}^{2}$.

It can be seen from Fig. 9 that, along with the rise of inflow speed, the average particle size of the generated powder increases significantly, yet the particle size distribution becomes increasingly irregular, the particles appear in the distinct shape of polygon, and the cohesion between particles is lessened significantly. Generally, the average size of the liquid droplet formed through a dual-fluid nozzle can be calculated according to the formula (1). ${ }^{15)}$

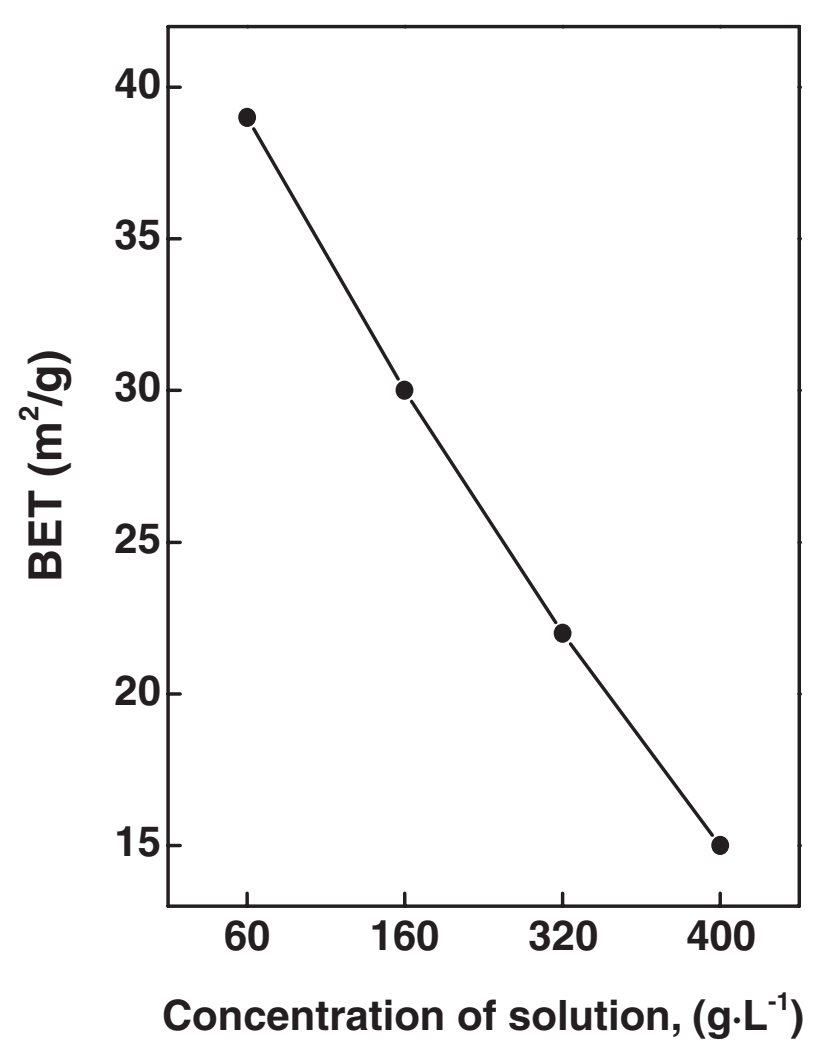

Fig. 8 Specific surface areas of powder according to indium concentration of raw material solution at $900^{\circ} \mathrm{C}, 10 \mathrm{~mL} / \mathrm{min}$. inlet speed of solution, $2 \mathrm{~mm}$ nozzle tip size and $1 \mathrm{~kg} / \mathrm{cm}^{2}$ air pressure.

$$
X=585 \frac{\sqrt{\sigma}}{v \sqrt{\rho}}+579\left(\frac{\mu}{v \sqrt{\sigma \rho}}\right)^{0.45} \frac{1000 Q_{t}^{1.5}}{Q_{a}}
$$

Where $X$ is the average size of the liquid droplet, $\mathrm{Q}_{l}$ is the amount of the solution, $Q_{a}$ is the amount of air, and $\sigma, \nu$ and $\mu$ are, respectably, the surface tension, spraying speed and viscosity of the solution.

When the inflow speed of the raw material solution is at the lowest $2 \mathrm{~mL} / \mathrm{min}$, the micronized liquid droplets appear with an extremely small size, and there is almost no droplet burst in the pyrolysis process. Hence, the average particle size of the generated powder is extremely small (below $30 \mathrm{~nm}$ ), and the particle size distribution appears comparatively uniform, yet the ultra-fine particles show a strong tendency of mutual cohesion. On the other hand, when there is a large amount of micronized small-size droplets, the cohesion between droplets becomes rapid and noticeable. In formula (2), ${ }^{16)}$ assuming that Brown movement is the cause of the collisions between droplets, and that $\beta$ is a constant, the possibility of cohesion between the initially micronized droplets increases considerably along with the reduction of droplet size.

$$
\left(\mathrm{N}_{\mathrm{t}} / \mathrm{N}_{\mathrm{t}}\right)=1 /\left(1+\mathrm{t} / \tau_{\mathrm{c}}\right)
$$

Where No is the amount of preliminarily micronized droplets, $\mathrm{Nt}$ is the amount of droplets at the time of $\mathrm{t}, \mathrm{Tc}$ is $2 / \beta$ and $\beta$ is the cohesion speed constant.

Therefore, before the start of pyrolysis reaction, small-size droplets resulting from the slow inflow speed of the solution and enlarged droplets resulting from the cohesion between droplets are expected to coexist, and the particle size 


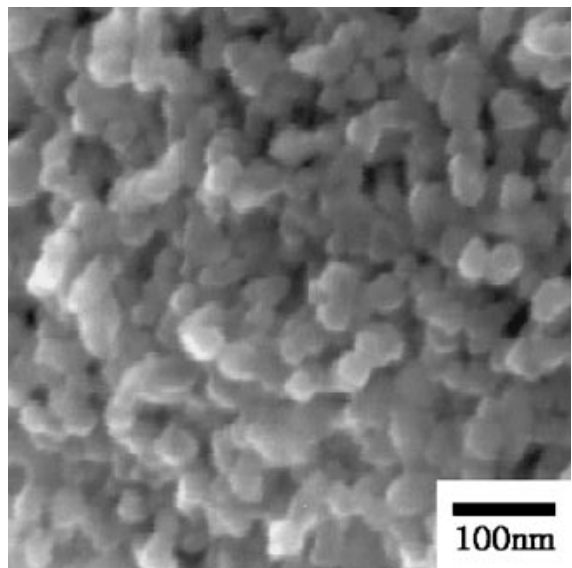

(a)

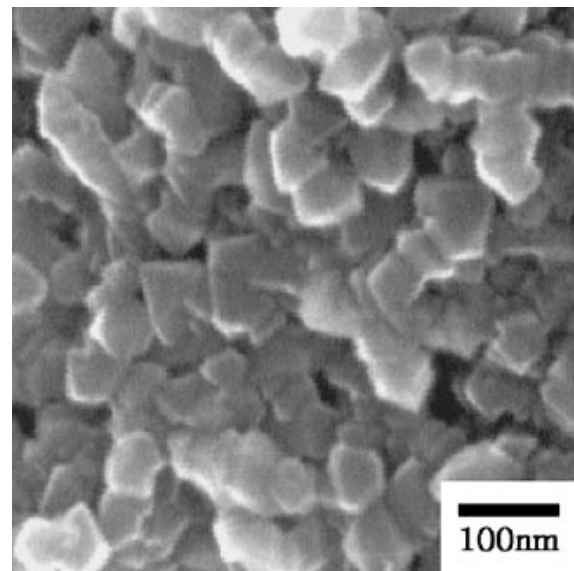

(c)

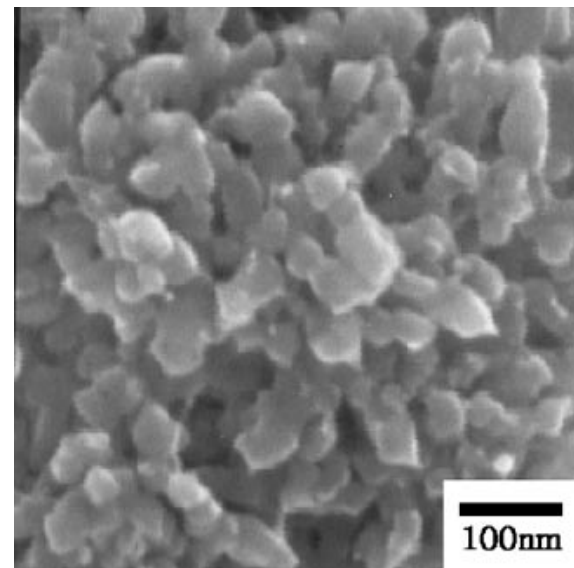

(b)

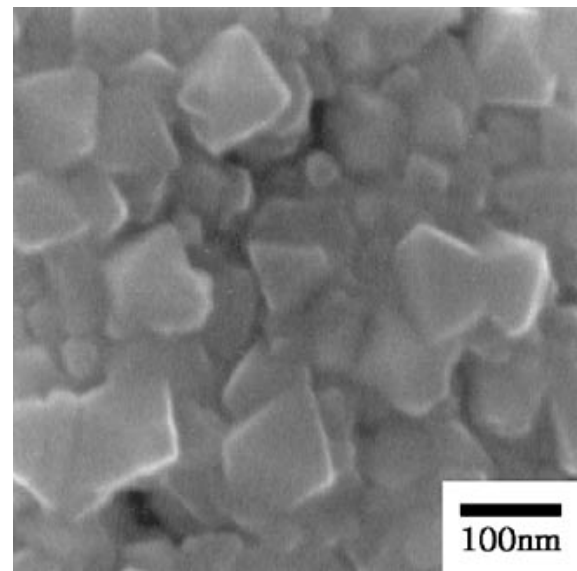

(d)

Fig. 9 SEM photographs of produced powder according to inlet speed of solution at $900^{\circ} \mathrm{C}$, raw material solution of $320 \mathrm{~g} / \mathrm{L}$ indium, $2 \mathrm{~mm}$ nozzle tip size and $1 \mathrm{~kg} / \mathrm{cm}^{2}$ air pressure. (a) $2 \mathrm{~mL} / \mathrm{min}$, (b) $10 \mathrm{~mL} / \mathrm{min}$, (c) $20 \mathrm{~mL} / \mathrm{min}$, (d) $100 \mathrm{~mL} / \mathrm{min}$.

distribution of the eventually generated powder shall be extremely irregular. In this study, however, the lessened droplet burst caused by the reduced droplet size predominantly influences the average particle size and particle size distribution. When the inflow speed increases up to $10 \mathrm{~mL} /$ min, there are simultaneously the following two effects, which are 1) because the size of micronized droplets increases significantly, the over-saturation on the droplet surface results in the pressure rise inside the droplets, and the droplet burst become much severer; 2) because the initially micronized droplets appear with a comparatively large size, and because the heat of evaporation during the pyrolysis process increases along with the rise of inflow speed, the droplet burst is lessened. As a result of above two effects, the average particle size of the eventually generated powder increases up to $60 \mathrm{~nm}$, yet the particle size distribution becomes much more irregular. When the inflow speed increases up to $20 \mathrm{~mL} / \mathrm{min}$, the heat of evaporation increases along with the rise of inflow speed, and the droplet burst is lessened. However, the growing size of micronized droplets along with the rise of inflow speed may cause the severer droplet burst. As a result, the average particle size of the eventually generated powder increases slightly in contrast to the situation at $10 \mathrm{~mL} / \mathrm{min}$. When the inflow speed increases up to $100 \mathrm{~mL} / \mathrm{min}$, between the aforementioned two effects, the second one plays a dominant role, and the particle size distribution appears comparatively irregular, yet the average particle size increase greatly up to above $90 \mathrm{~nm}$.

Figure 10, the result of XRD analysis under the same reaction conditions as in Fig. 9, shows the phases of the generated powder and the corresponding Miller index of each peak relative to the change of inflow speed of the raw material solution. When the inflow speed increases from the lowest $2 \mathrm{~mL} / \mathrm{min}$ to the highest $100 \mathrm{~mL} / \mathrm{min}$, the only existing form of the generated powder is ITO no matter what level the inflow speed is at. This result is the combined effect of the following two mechanisms: 1) when the inflow speed is at the low level, according to formula (1), the droplet size is extremely small, hence there is no too much heat of evaporation released during the pyrolysis process, and the pyrolysis reaction proceeds completely into the inside of droplets within a short period of time; 2) when the inflow speed is at the high level, e.g. $100 \mathrm{~mL} / \mathrm{min}$, there is a significant rise of droplet size, the heat of evaporation increases accordingly and the evaporation of solvent takes much longer time, therefore there is sufficient oxygen supply during the pyrolysis process, and the pyrolysis reaction proceeds completely. It can also be seen from Fig. 10 that 


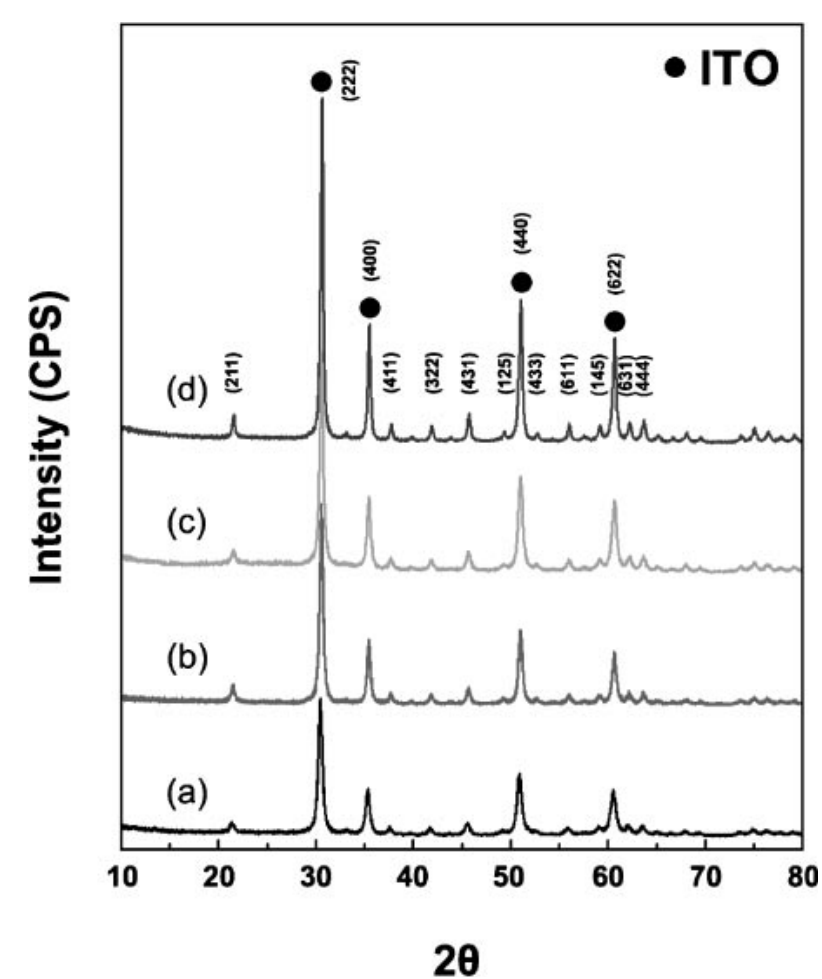

Fig. 10 XRD patterns of powder according to inlet speed of solution at $900^{\circ} \mathrm{C}$, raw material solution of $320 \mathrm{~g} / \mathrm{L}$ indium, $2 \mathrm{~mm}$ nozzle tip size and $1 \mathrm{~kg} / \mathrm{cm}^{2}$ air pressure. (a) $2 \mathrm{~mL} / \mathrm{min}$, (b) $10 \mathrm{~mL} / \mathrm{min}$, (c) $20 \mathrm{~mL} / \mathrm{min}$, (d) $100 \mathrm{~mL} / \mathrm{min}$.

the XRD peak intensity gradually increases along with the rise of inflow speed. As the inflow speed increases from $2 \mathrm{~mL} / \mathrm{min}$ to $10 \mathrm{~mL} / \mathrm{min}$, the XRD peak intensity increases significantly. As the inflow speed increases up to $20 \mathrm{~mL} / \mathrm{min}$, however, there is only a slight rise of XRD peak intensity. This result is almost consistent with the changing tendency of average particle size shown in Fig. 9. When the inflow speed increases up to $100 \mathrm{~mL} / \mathrm{min}$, because of the increase of droplet size and heat of evaporation, the XRD peak intensity increases significantly.

Figure 11 shows the specific surface area of the generated powder relative to the inflow speed of the raw material solution under the same reaction conditions as in Fig. 9. It can be seen from Fig. 11 that the specific surface area of the generated powder decreases greatly along with the rise of inflow speed. Especially as the inflow speed increases from $20 \mathrm{~mL} / \mathrm{min}$ to $100 \mathrm{~mL} / \mathrm{min}$, the specific surface area decreases by half. This result, consistent with what is shown in Fig. 9, is owing to the fact that the average particle size of the generated ITO powder is proportional to the inflow speed of raw material solution. The reason for the fall of specific area is because that, along with the rise of inflow speed, the droplet size also increases, and that the droplet burst diminishes due to the increasing heat of evaporation.

\section{Conclusions}

In this study, a complex acid solution made from waste ITO target undergoes pyrolysis reaction to generate a nanosized ITO powder with the average particle size below $50 \mathrm{~nm}$.

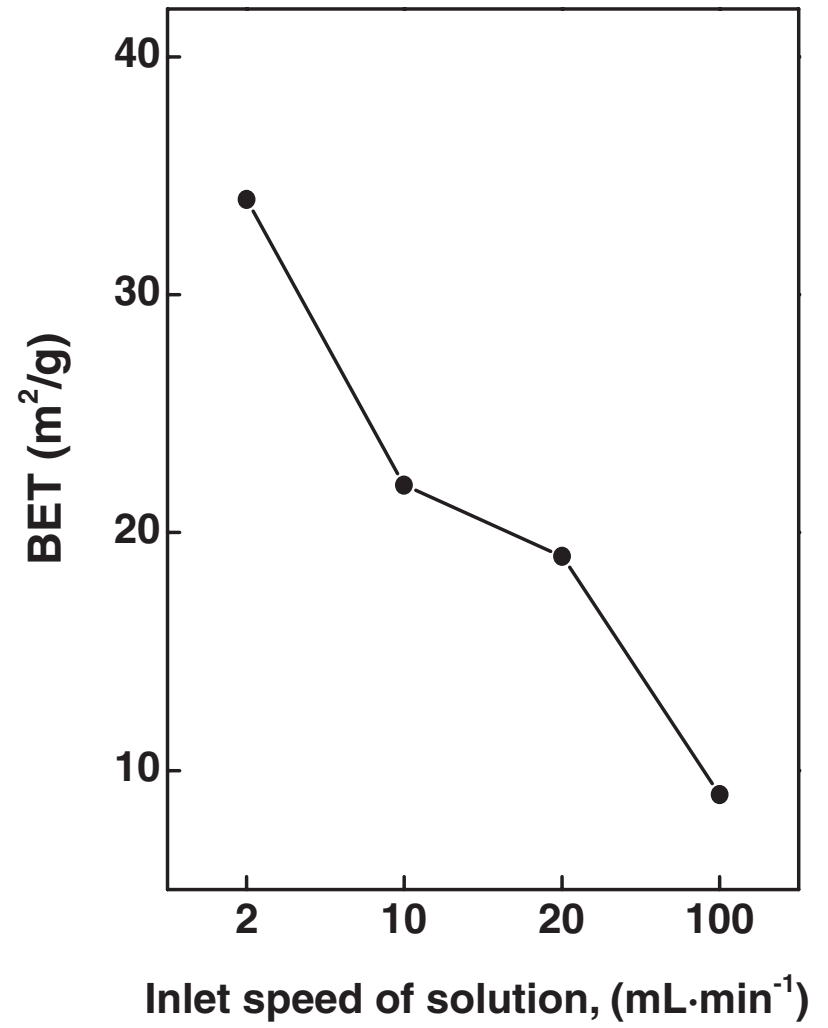

Fig. 11 Specific surface areas of powder according to inlet speed of solution at $900^{\circ} \mathrm{C}$, raw material solution of $320 \mathrm{~g} / \mathrm{L}$ indium indium, $2 \mathrm{~mm}$ nozzle tip size and $1 \mathrm{~kg} / \mathrm{cm}^{2}$ air pressure.

This study also examines the influences of various reaction parameters on the properties of the generated powder. These parameters include the reaction temperature, the concentration and inflow speed of raw material solution.

(1) As the reaction temperature increases from 800 to $1100^{\circ} \mathrm{C}$, the average particle size of the generated ITO powder increases from $40 \mathrm{~nm}$ to $100 \mathrm{~nm}$, the microstructure gradually becomes compact, and individual particles appear independently in the shape of polygon. Along with the temperature rise, the particle size distribution becomes increasingly irregular, the XRD peak intensity gradually increases, and the specific surface area decreases.

(2) When the concentration of the raw material solution is at $50 \mathrm{~g} / \mathrm{L}$, the average particle size of the generated ITO powder is below $30 \mathrm{~nm}$, and the particle size distribution appears comparatively uniform. As the concentration increases up to $160 \mathrm{~g} / \mathrm{L}$ and $320 \mathrm{~g} / \mathrm{L}$, the average particle size accordingly increases up to 50 $\mathrm{nm}$, yet the particle size distribution gradually becomes irregular. When the concentration reaches $400 \mathrm{~g} / \mathrm{L}$, which is close to the saturated concentration, the particle size distribution appears extremely irregular, and the particles with the size ranging from $20 \mathrm{~nm}$ to $100 \mathrm{~nm}$ coexist. As the concentration increases from $50 \mathrm{~g} / \mathrm{L}$ to $400 \mathrm{~g} / \mathrm{L}$, the XRD peak intensity gradually increases, yet the specific surface area decreases.

(3) When the inflow speed of the raw material solution is at $2 \mathrm{~mL} / \mathrm{min}$, the average particle size of the generated ITO powder is below $30 \mathrm{~nm}$, the particle size distribu- 
tion appears comparatively uniform, yet the cohesion between particles occurs remarkably. As the inflow speed of the raw material solution increases up to 10 $\mathrm{mL} / \mathrm{min}$ and $20 \mathrm{~mL} / \mathrm{min}$, the average particle size increases to above $60 \mathrm{~nm}$, yet individual particles appear in the distinct shape of polygon. When the inflow speed increases up to $100 \mathrm{~mL} / \mathrm{min}$, the particle size distribution appears comparatively irregular, yet most of the particles appear in the form of independent particles, and the average particle size increases to above $90 \mathrm{~nm}$. Along with the rise of inflow speed, the XRD peak intensity gradually increases, and the specific surface area decreases.

\section{Acknowledgements}

This work was supported by the Regional Innovation Center of Hoseo University and the Ministry of Science \& Technology in Korea.

\section{REFERENCES}

1) A. Antony, M. Manoj and M. K. Jayaraj: Appl. Surf. Sci. 225 (2004) 294-301.
2) L. R. Cruz, C. Legnani, I. G. Matoso, C. L. Ferreira and H. R. Moutinho: Mat. Res. Bull. 39 (2004) 993-1003.

3) Y. Hu, X. Diao, C. Wang, W. Hao and T. Wang: Vacuum 75 (2004) $183-188$.

4) K. Maki, N. Komiya and A. Suzuki: Thin Solid Films 445 (2003) 224248.

5) S. Tang, J. Yao, J. Chen and J. Luo: J. Mater. Process. Technol. 137 (2003) 82-85.

6) S. G. Chen, C. H. Li, W. H. Xiong, L. M. Liu and H. Wang: Mater. Lett. 58 (2002) 294-298.

7) P. S. Devi, M. Chatterjee and D. Ganguli: Mater. Lett. 55 (2002) 205210.

8) C. P. Udawatte and K. Yanagisawa: J. Am. Ceram. Soc. 84 (2001) 251253.

9) K. Yanagisawa, C. P. Udawatte and N. Nasu: J. Mater. Res. 15 (2000) 1404-1408.

10) J. K. Yu, S. G. Kang, J. B. Kim, J. Y. Kim, J. S. Han, J. W. Yoo, S. W. Lee and Z. S. Ahn: Mater. Trans. 47 (2006) 1695-1700.

11) J. K. Yu, G. H Kim, T. S. Kim and J. Y. Kim: Mater. Trans. 46 (2005) 1695-1700.

12) T. G. Carreno, M. P. Morales and C. J. Serna: Mater. Lett. 43 (2000) 97-100.

13) M. A. A. Elmasry, A. Gaber and E. M. H. Khater: Powder Technology 90 (1997) 165-168.

14) D. Majumdar, T. A. Shefelbine and T. T. Kodas: J. Mater. Res. 11 (1996) 2861-2868.

15) S. C. Zhang and G. L. Messing: J. Am. Ceram. Soc. 73 (1990) 61-67.

16) G. L. Messing, S. C. Zhang and G. V. Jayanthi: J. Am. Ceram. Soc. 76 (1993) 2707-2726. 